\title{
Tongue and lingual salivary glands of the canary: scanning electron microscopy and histochemical study
}

\author{
F. Başak', Ş.H. Atalgin², E.Ü. Bozkurt ${ }^{3}$ \\ ${ }^{1}$ Department of Histology and Embryology, Faculty of Veterinary Medicine, Mustafa Kemal University, Hatay, Turkey \\ ${ }^{2}$ Department of Anatomy, Faculty of Veterinary Medicine, Balıkesir University, Balıkesir, Turkey \\ ${ }^{3}$ Department of Anatomy, Faculty of Veterinary Medicine, Kırıkkale University, Kırıkkale, Turkey
}

[Received: 28 December 2016; Accepted: 10 February 2017]

\begin{abstract}
In this study, morphological characteristics of the canary tongue were examined macroscopically and histologically besides using scanning electron microscopy. Furthermore, histochemical features of the lingual salivary glands of the canary were also examined. The results suggest that the tongue of the canary has an equilateral quadrangle shape is sloped towards the apex on its dorsal surface; where its sides are bounded by tall epithelial extensions. Additionally, histological examination showed that salivary glands were only present on the body of the tongue and there were no taste buds. However, the tongue has mechanical sensory cell groups in its subepithelial connective tissue. Histochemical examination, demonstrated that the salivary gland epithelial cells contained carbohydrates which were composed of acidic sialo-mucins. (Folia Morphol 2017; 76, 3: 348-354)
\end{abstract}

Key words: canary, tongue, surface morphology, scanning electron microscopy, lingual salivary glands, histochemistry

\section{INTRODUCTION}

The oral cavity, tongue morphology and ultrastructure of the tongue surface have been examined in the studies performed on different avian tongues $[4,6,8-17,23,25-27,29,32,38-41)$. Various studies performed on different avian species have described the shape and the covering epithelial surface of tongue and proposed that these features are closely associated with nutritional habits. In other words, the morphology of the tongue reflects the functional and characteristic adaptations $[18,26]$. In comparison with morphological studies, there are limited number of histochemical studies in which the features of lingual salivary glands have been examined $[1,3,5,7,19,45]$. However, studies performed on canaries (Serinus canaria forma domestica) generally focus on the physiology of the nervous system $[2,22,28,37,42]$.
The structure and the function of the tongue and lingual salivary glands provide information about the diet as well as adaptations to the animals' habitat. In addition, these features are also important for the food, poultry and pharmaceutical industries since they also provide information about food digestion, and the potential modulatory effects of saliva on taste [33]. Saliva, with its carbohydrate content, is important for the transportation of macromolecules for digestion and plays a role in the protection of the oral cavity mucosa from bacteria [20]. No study reports seed eater canary's tongue and salivary glands' morphological structure.

The aim of this study was to examine the structurefunction relationship in the canary, especially the shape of the tongue and epithelium with respect to its functional and morphological features as well as histochemical characteristics of the lingual salivary glands. 


\section{MATERIALS AND METHODS}

Eight tongues from dead canaries right after their death and before autolysis began were collected from canary and pet shops for use as teaching material in practical courses of Balıkesir University Faculty of Veterinary Medicine. The tongues were fixed in 10\% neutral buffered formalin solution for $24-72 \mathrm{~h}$ in room temperature. The tongues were dissected and photographed.

The materials were set in paraffin blocks after fixation for examination with light microscopy. Sections, 5-micrometer thick, were taken from these blocks and stained with haematoxylin and eosin [46], periodic acid-Schiff (PAS) for neutral mucins (395B, SigmaAldrich, St. Louis, MO, USA), AB pH 1.0 and AB pH 2.5 for acidic mucins $[30,44]$, and to distinguish acidic and neutral mucins PAS-AB pH 1.0 [44] and PAS-AB pH 2.5 [36]. To distinguish sulphomucins and sialomucins [43] sialidase (from Clostridium perfringens) (N2876, Sigma-Aldrich, St. Louis, MO, USA)-AB pH 2.5 [44], diastase (from Aspergillus oryzae) (09962, Sigma-Aldrich, St. Louis, MO, USA)-PAS [35], hyaluronidase (from bovine testis) (H3506, Sigma-Aldrich, St. Louis, MO, USA)-AB 2.5 [44], weak, mild and strong methylation were applied. The sections were examined and photographed with an Olympus sc 100 camera system and cellSens Entry computer imaging system attached to CX21 Olympus binocular microscope.

The specimens taken for scanning electron microscopy (SEM) examinations were fixed in $0.5 \%$ glutaraldehyde solution buffered with $1 \%$ sodium acetate containing $3 \% \mathrm{HgCl}_{2}$. The fixed tongues were dehydrated and the critical point dry was obtained with Polaron Critical Point Drier, and specimens were coated with gold with Polaron Sputter Coater, examined and photographed with JSM5600 $30 \mathrm{kV}$ SEM. Measurements were made in 7 canary tongues using an image $J$ computer programme (1.36b, Wayne Rasband National Institutes of Health, USA) for macroscopic and microscopic evaluation. One canary tongue was excluded from evaluation due to technical reasons. Mc Lelland (1993) was used for denomination [34].

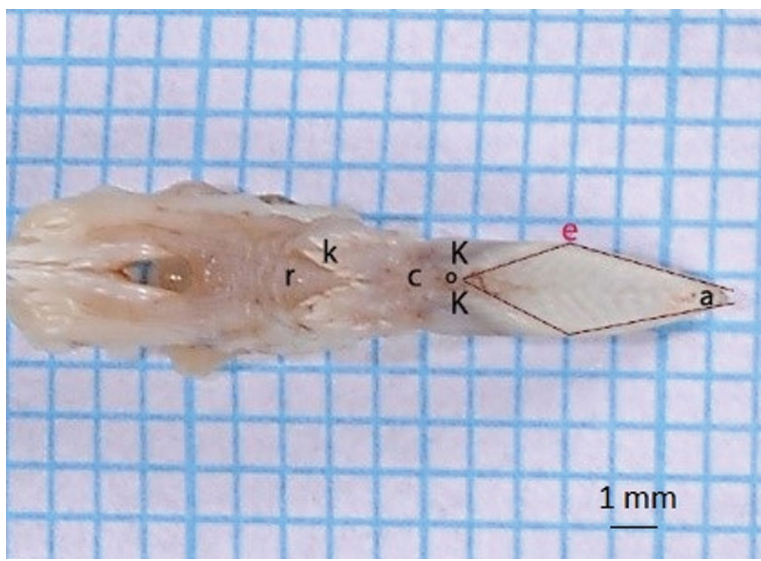

Figure 1. Macroscopic view of the canary tongue (dorsal); $a-$ apex linguae; $c$ - corpus linguae; $r$ - radix linguae; $k$ - conical papillae; $\mathrm{K}$ - prominent edges; $\mathrm{e}$ - equilateral quadrangle surface; 0 - groove.

\section{RESULTS}

\section{Macroscopy}

The canary tongue was divided into three parts; apex, corpus and radix linguae (Fig. 1 [a, c, r]). Lengths of the tongue parts are given in Table 1.

The tongue had a triangle apex which was parallel to the edges of the lower beak and it was long. Furthermore, the tongue did not entirely fill the oral cavity. The upper surface of the tongue contained an equilateral quadrangle area (Fig. 1 [e]) with prominent edges (Fig. 1 [k]) which sloped from body to tip with approximately $15^{\circ}$ inclination (Fig. 1, 2, 3 [a]). The sloping surface was bounded by thick edges on both sides of the corpus region and between the edges there was a groove which became wider towards the radix (Fig. 1 [o]). A transverse row of conical papillae was located at the border between radix and the corpus. This row was aligned in the shape of " $\mathrm{W}$ " with its base pointing towards the radix. All papillae were less than $1 \mathrm{~mm}$ in length (Fig. 1 [k]).

There were no prominentia lingualis or sulcus lingualis. The lower surface of the tongue was convex from apex to radix.

Table 1. Average size measurements from 7 canary tongues (millimetre)

\begin{tabular}{lccccc}
\hline & Apex length & Body length & Root length & Body width & Root width \\
\hline Mean & $2.366 \pm 0.569$ & $5.970 \pm 1.725$ & $2.582 \pm 0.859$ & $2.457 \pm 0.988$ & $2.808 \pm 0.906$ \\
\hline
\end{tabular}




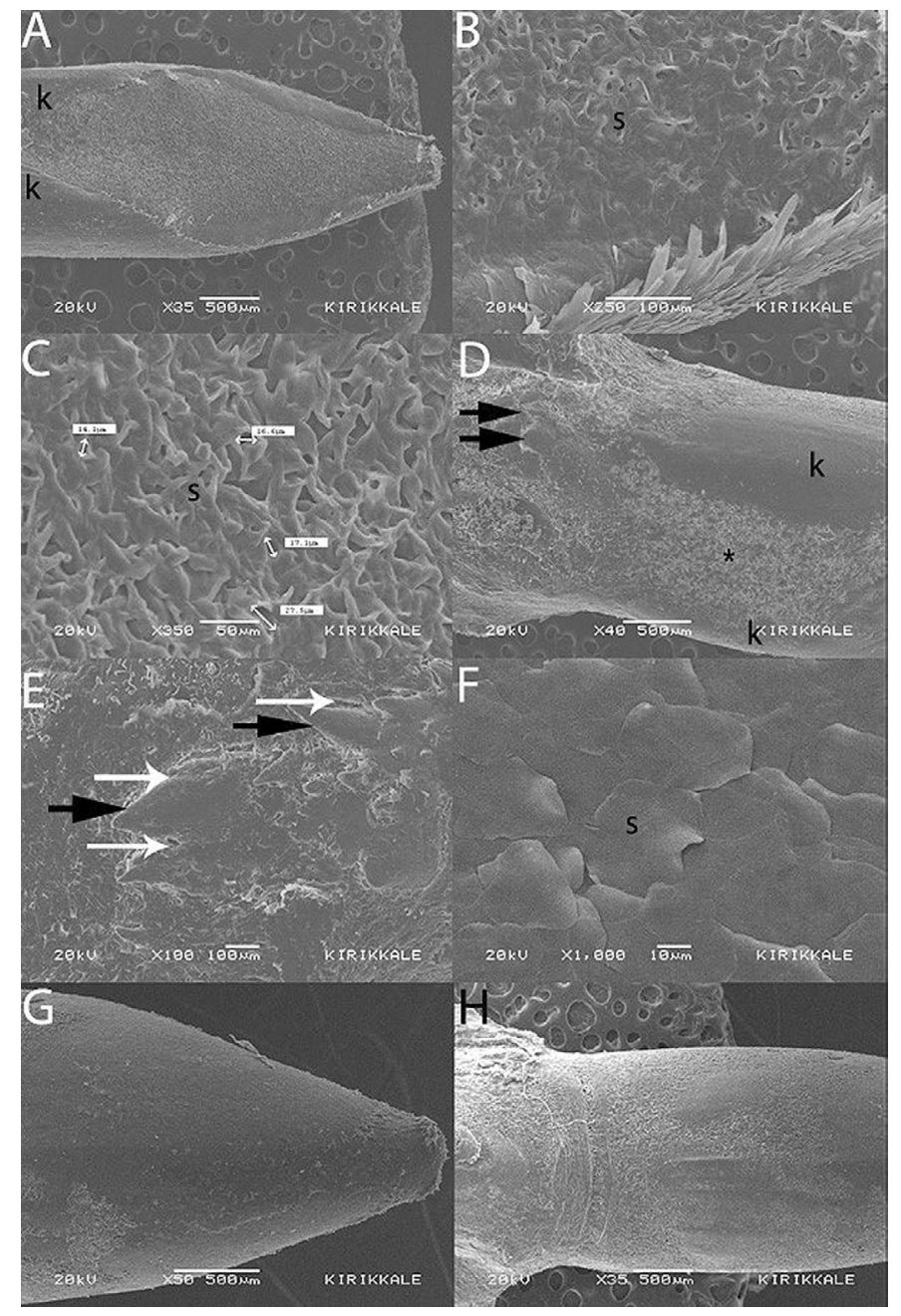

Figure 2. Scanning electron microscopic views of the canary tongue; A, B, C, D, E. Dorsal; F, G, H. Ventral; A: kthick edges; $\mathbf{B}: \mathbf{s}$ - squamous epithelium; C: $\mathbf{s}$ - squamous epithelium; white arrows - duct openings of lingual salivary glands; D: $\mathrm{k}$ — thick edges; asterisk — squamous epithelium; black arrows — conical papillae; E: black arrows - conical papillae; white arrows - duct openings of lingual salivary glands; F: s - squamous epithelium; G: Ventral lingual surface (apex); H: Ventral lingual surface (corpus and radix).

\section{Scanning electron microscopy}

In the SEM images, the dorsal surface of the tongue (Fig. 2A, B) had prominent boundaries formed by needlelike apical lateral side extensions (Fig. 2A, B, D [k]). There were various multilayer squamous cells on the inclined surface located on the dorsal surface (Fig. 2B, C [s], $D\left[{ }^{*}\right]$ ) and there were also a large number of salivary gland excretory duct openings varying in width from $7.55 \mu \mathrm{m}$ to $27.5 \mu \mathrm{m}$ (Fig. 2C). There were no salivary gland excretory ducts on the edges of the corpus of the tongue. There were similar structures within the upper surface of the apex, between the thick edges on both sides of the corpus region (Fig. 2D [*]).

There were 100-335 $\mu \mathrm{m}$ long conical papillae which could only be observed by SEM at the dorsal surface of the body. They were spread out irregularly between the corpus and radix with their tips towards the radix (Fig. 2D, E [black arrows]). Using SEM it could be clearly seen that there were wide-mouthed salivary gland ex- cretory ducts between the conical papillae similar to the ones located on the apex and radix of the tongue (Fig. 2D, E [white arrows]).

On the electron microscopy images, the entire lower surface of the tongue was covered with squamous cells (Fig. 2F [s]), there were very small openings of salivary gland excretory ducts in the corpus and radix area (Fig. $2 \mathrm{H}$ ), and it was seen that ventral side of the apex was quite smooth compared to the corpus and radix (Fig. 2G, H).

For histologic examination tongue sections were stained using haematoxylin and eosin staining (Fig. 3). The epithelium was thicker on the dorsal side compared to ventral surface (Fig. 3 [DE, VE]). The epithelial thickness of the ventral surface measured $70 \mu \mathrm{m}$ at the apex, corpus and radix. On the dorsal surface of the tongue, the multiple squamous epithelium reached to its maximum thickness $(1 \mathrm{~mm})$ at the apex of the tongue. Furthermore, the thickness gradually decreased caudally, 


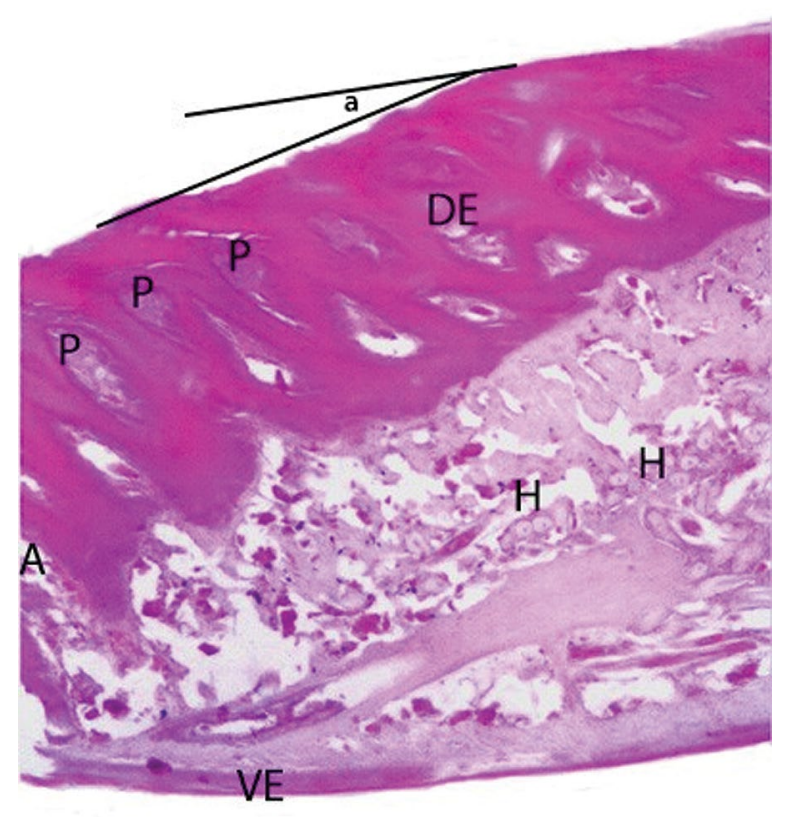

图

Figure 3. Histologic section of canary tongue $(5 \mu \mathrm{m})$, haematoxylin and eosin ( $\times 4)$; DE — dorsal epithelium; VE — ventral epithelium; $\mathrm{A}$ - apex linguae; $\mathrm{P}$ - microscopic papillae; $\mathrm{H}$ - herbst corpuscles; a - equilateral quadrangle inclined surface angle.

with a minimum thickness of $400 \mu \mathrm{m}$ at the radix of the tongue. There was more keratinised epithelium on the dorsal compared with the ventral surface of the tongue. There were various microscopic connective tissue papilla extensions from the submucosa towards epithelium (Fig. 3 [P]). The cartilaginous components of the Os entoglossum did not reach the corpus of the tongue.

Salivary glands were bilaterally located only in the posterior side of the corpus and there were no salivary glands at the apex or rostral to the corpus (Fig. 3 [A]). Lingual salivary glands were covered by a connective tissue capsule and divided the simple tubuloalveolar tissue into lobules by sending arms into it (Fig. 4). Glandular cells were similar in gland body.

The tongue was poorly vascularized, has small amount of muscles and no adipocytes. Lingual muscles formed a very thin layer close to ventral surface of tongue. Herbst corpuscles which are analogous to Pacinian corpuscles in mammals were detected at the corpus area in the submucosal connective tissue of the tongue. These Herbst corpuscles were in cell groups almost $50 \mu \mathrm{m}$ diameter (Fig. $3[\mathrm{H}]$ ).

\section{Histochemistry}

The staining methods were selected to determine the carbohydrate type of the secretions of the lingual salivary glands of the canary tongue.

Periodic acid-Schiff staining was used to determine glycogen and/or other periodate reactive carbohydrates in the secretory cells of the lingual salivary gland and their secretion. Weak staining with PAS (Fig. 4A) indicates there were small amounts of glycogen in the gland cells and secretions. The salivary glands stained purple with PAS after diastase enzyme digestion (Fig. 4B). This indicates that the weak glycogen content of the glands is converted to carbohydrates such as maltose which can be dissolved in water, with diastase enzyme digestion resulting in decreased staining with PAS.

In the sections stained with $A B \mathrm{pH} 1.0$ (Fig. 4C) and $A B \mathrm{pH} 2.5$ (Fig. $4 \mathrm{D}$ ) brilliant blue staining indicates that the salivary glands contain acidic carbohydrates such as sialidase-sensitive acidic sialomucins and/or hyaluronidase-resistant sulphomucins.

In order to distinguish the acidic and neutral mucins, PAS-AB pH 1.0 (Fig. 4E) and PAS-AB pH 2.5 (Fig. 4F) staining was performed. Persisting brilliant blue colour after AB pH 1.0 staining followed by PAS staining confirms that the carbohydrate content of the Canary lingual salivary gland has acidic, sialidase-sensitive sialomucin but no neutral mucins.

A considerable decrease in colour occurred in sections which were stained with $A B \mathrm{pH} 2.5$ after hyaluronidase enzyme digestion (Fig. 4J). Hyaluronidase removes hyaluronic acid and glycosidic bonds from other glycosaminoglycans and indicates that there were strongly sulphated mucins, mostly acidic mucins in connective tissue.

In comparison with the control slides, there was a slight loss of staining in the sections stained by $A B$ $\mathrm{pH} 2.5$ after performing the weak and moderate methylation procedure (Fig. 4G, H). However, in sections in which strong methylation was applied there was no reaction with $A B$ pH 2.5 (Fig. 4I). These results indicate that there were sulphate-containing carbohydrates rather than carboxyl group-containing carbohydrates and these sulphomucins were acid-resistant in the Canary lingual salivary glands.

Sialidase enzyme digestion and then $\mathrm{AB}$ pH 2.5 treatments were performed to determine if carboxylic mucins were sensitive or resistant to sialidase enzyme. A considerable decrease in staining was observed (Fig. 4K) which indicates that the lingual salivary gland mucins were sensitive to sialidase enzyme digestion. 


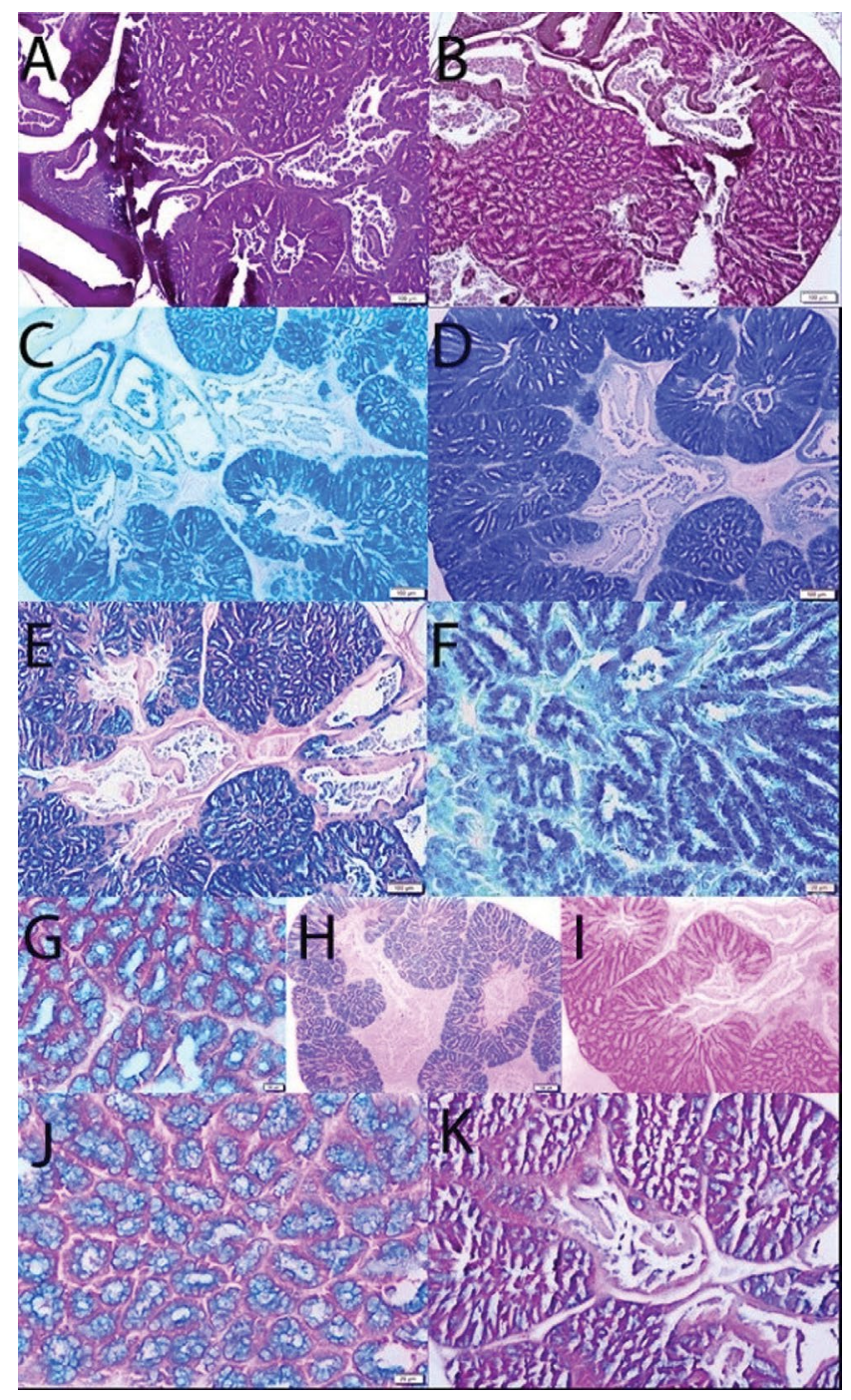

Figure 4. Histochemical views of lingual salivary glands in canary tongue sections $(5 \mu \mathrm{m})$; A. periodic acid-Schiff (PAS) $(\times 10)$; B. Diastase enzyme digestion-PAS $(\times 10)$; C. $A B \mathrm{pH}$ $1.0(\times 10)$; D. AB pH $2.5(\times 10)$; E. PAS-AB pH $1.0(\times 40)$; F. PAS-AB pH $2.5(\times 40)$; G. Weak methylation procedure-AB $\mathrm{pH} 2.5(\times 40) ; \mathbf{H}$. Moderate methylation procedure- $\mathrm{AB} \mathrm{pH} 2.5$ $(\times 10)^{\prime}$ I. Strong methylation procedure-AB pH $2.5(\times 10)$; J. Hyaluronidase enzyme digestion-PAS $(\times 40)$; K. Sialidase enzyme digestion-AB pH 2.5-Neutral red $(\times 10)$.

\section{DISCUSSION}

Canaries are primarily fed seeds. Although no spinous papillae (or any other specific structures which have been reported as modification in tongues used for collecting food [18] were observed on the dorsal surface of the tongue, there were needle-like apical lateral side processes. The canary tongue is not protrusible and is similar to tongues specialized for collecting food in the classification of Erdogan and Iwasaki [18]. Needle-like apical lateral side processes have forward facing ends not backward facing and in this way are different from geese which have hair-like side extensions known as papillae filiformis. Furthermore, there are no beak protrusions at the edges of the upper or lower beak as is the case in geese [26]. Therefore, it is thought that these epithelial extensions, which limit the lateral edges of the inclined surface of the upper part of the tongue, could play a role in keeping the food on the tongue surface until it is swallowed $[24,29]$.

The canary tongue has thicker epithelium on the dorsal surface compared with the ventral surface, and this gradually decreases in thickness towards radix, and these findings are similar to those reported in the literature [18, $19,24,26,29]$. Since the epithelial keratinization of the canary tongue is limited, it may suggest that food stays limited period on dorsal surface of the tongue is limited.

The components of the hyobranchial apparatus did not extend into the body of the tongue and anterior part of the tongue was entirely free of bone and cartilage. The corneal lingual cuticula (lingual nail) which supports the tongue from the lower surface was not formed. In addition, intrinsic lingual muscle group was a very thin layer close to ventral surface of the tongue and may have mechanical effect on lingual apparatus 
of the canary tongue. The papillary crest was located between the corpus and radix of the dorsal surface of the tongue and the transverse row of papillae on the boundary between the radix and corpus. The Backward facing conical papillae may have a mechanical effect during swallowing, preventing food from moving towards the front of the oral cavity.

When the food is transported to the radix of the tongue, it must be mixed with mucus for easy swallowing. It was therefore surprising that the diameter of salivary gland excretory ducts became smaller at the front part of the tongue body (between 7.55 and $27.5 \mu \mathrm{m}$ ) whereas these ducts were larger at the posterior corpus and the root of the tongue $(100 \mu \mathrm{m})$.

There were small salivary gland excretory ducts on the underside of the tongue except at the apex. The secretions form these may facilitate the movement of the tongue in the lower beak.

Gentle [21] reported finding 8-15 taste buds which connected to the channels of the salivary glands and were located on the dorsal surface of the tongue just behind the transversal papillae row in young and adult male and female broilers. There are intraepithelial gustatory buds in many avian species too [18]. According to the histological examination results of this study there were no taste buds in the epithelium in any part of the tongue despite serial sections taken from the whole tongue being examined.

Gargiulo et al. [20] and Liman et al. [31] reported that the carbohydrate contents of the lingual salivary glands were locally different in quails. In this study, the same reactions were observed in all parts of the salivary glands so it was thought that the carbohydrate contents of lingual salivary glands were homogeneous.

\section{CONCLUSIONS}

In conclusion, we have shown that the specific morphological features of the canary tongue include a markedly inclined and wide surface at the upper side of the tongue which starts at the corpus and tapers towards the apex. Lingual salivary glands are located in the front of the radix and at the back of the corpus; and there are no taste buds in the tongue. The histochemical results suggest that the carbohydrate content of the saliva is homogenous and contains mainly acidic sialo-mucins which can bind to the galactosyl groups of the carbohydrates as in the chicken [20]. Canary saliva glucoconjugate content has similarity of Garrulus glandarius which has Type IV saliva [5] except to its secretion includes sialic acid and other acid proteoglycans.
Canary saliva seems to have a protective effect on oral mucosa since it helps to hydrate the mucosal surface of the tongue and facilitate ingestion as reported in the literature [18]. The question of whether it has an effect on taste perception in canaries, which have no lingual taste buds, remains to be answered.

\section{REFERENCES}

1. Almansour MI, Jarrard BM. Morphological, histological and histochemical study of the lingual salivary glands of the little egret, egretagarzetta. Saudi J Biol Sci. 2007; 14(1): 75-81.

2. Alvarez-Buylla A, Theelen M, Nottebohm F. Birth of projection neurons in the higher vocal center of the canary forebrain before, during, and after song learning. Proc Natl Acad Sci USA. 1988; 85(22): 8722-8726, indexed in Pubmed: 3186755.

3. Arthitvond S, Makmee N, Suprasertark A. Histochemical detection of glycoconjugates in the anterior lingual salivary glands of the domestic fowl. Kasetsart J Nat Sci. 1999; 33: 243-250.

4. Bailey TA, Mensah-Brown EP, Samour JH, et al. Comparative morphology of the alimentary tract and its glandular derivatives of captive bustards. J Anat. 1997; 191 ( Pt 3): 387-398, doi: 10.1046/j.1469-7580. .19130387.x, indexed in Pubmed: 9418995.

5. Calabrò C, Albanese M, Bertuccio C, et al. Glycosaminoglycans in the tongue of birds. Atti della Accademia Peloritana dei Pericolanti - Classe di Scienze Fisiche, Matematiche e Naturali. 2009; 87(1), doi: 10.1478/C1A0901004.

6. Crole MR, Soley JT. Surface morphology of the emu (Dromaius novaehollandiae) tongue. Anat Histol Embryol. 2010; 39(4): 355-365, doi: 10.1111/j.1439-0264.2010.01002.x, indexed in Pubmed: 20491751.

7. Crole M, Soley J. Distribution and structure of glandular tissue in the oropharynx and proximal esophagus of the emu (Dromaius novaehollandiae). Acta Zoologica. 2011; 92(3): 206-215, doi: 10.1111/j.1463-6395.2010.00457.x.

8. Dehkordi RAF, Parchami A, Bahadoran S. Light and scanning electron microscopic study of the tongue in the zebra finch cardueliscarduelis (aves: passeriformes: fringillidae). Slov Vet Res. 2010; 47(4): 139-44.

9. El Bakary NER. Comparative scanning electron microscope study of the dorsal lingual surface of meropesorientalis (Little green bee eater) and meropesepiaster (European bee eater). MEJSR. 2011; 9(3): 384-389.

10. El Bakary NER. Surface morphology of the tongue of the hoopoe (UpupaEpops). J Am Sci. 2011; 7(1): 394-399.

11. Emura S, Chen H. Scanning electron microscopic study of the tongue in the owl (Strix uralensis). Anat Histol Embryol. 2008; 37(6): 475-478, doi: 10.1111/j.1439-0264.2008.00871.x, indexed in Pubmed: 19032633.

12. Emura S, Okumura T, Chen H. Scanning electron microscopic study of the tongue in the rainbow lorikeet (Trichoglossus haematodus). Okajimas Folia Anat Jpn. 2011; 88(1): 17-21, doi: 10.2535/ofaj.88.17.

13. Emura S, Okumura T, Chen H. [SEM studies on the connective tissue cores of the lingual papillae of the northern goshawk (Accipiter gentilis)]. Kaibogaku Zasshi. 2008; 83(3): 77-80, indexed in Pubmed: 18807946.

14. Emura S, Okumura T, Chen H. Scanning electron microscopic study of the tongue in the Oriental scops owl (Otus scops). Okajimas Folia Anat Jpn. 2009; 86(1): 1-6, indexed in Pubmed: 19522300. 
15. Emura S, Okumura T, Chen H. Scanning electron microscopic study of the tongue in the Japanese pygmy woodpecker (Dendrocopos kizuki). Okajimas Folia Anat Jpn. 2009; 86(1): 31-35, doi: 10.2535/ofaj.86.3, indexed in Pubmed: 19522304.

16. Emura S, Okumura T, Chen H. Comparative studies of the dorsal surface of the tongue in three avian species by scanning electron microscopy. Okajimas Folia Anat Jpn. 2010; 86(4): 111-115, doi: 10.2535/ofaj.86.111, indexed in Pubmed: 20560446.

17. Emura $\mathrm{S}$, Okumura T, Chen H. Scanning electron microscopic study of the tongue in the Jungle Nightjar (Caprimulgus indicus). Okajimas Folia Anat Jpn. 2010; 86(4): 117-120, doi: 10.2535/ofaj.86.117., indexed in Pubmed: 20560447.

18. Erdoğan S, Iwasaki Si. Function-related morphological characteristics and specialized structures of the avian tongue. Ann Anat. 2014; 196(2-3): 75-87, doi: 10.1016/j. aanat.2013.09.005, indexed in Pubmed: 24219998.

19. Erdoğan S, Sağsöz H, Akbalik ME. Anatomical and histological structure of the tongue and histochemical characteristics of the lingual salivary glands in the Chukar partridge (Alectoris chukar, Gray 1830). Br Poult Sci. 2012; 53(3): 307-315, doi: 10.1080/00071668.2012.700507, indexed in Pubmed: 22978586.

20. Gargiulo AM, Lorvik S, Ceccarelli P, et al. Histological and histochemical studies on the chicken lingual glands. Br Poult Sci. 1991; 32(4): 693-702, doi: 10.1080/00071669108417395, indexed in Pubmed: 1933443.

21. Gentle MJ. The lingual taste buds of Gallus domesticus L. Br Poult Sci. 1971; 12(2): 245-248, doi: 10.1080/00071667108415876, indexed in Pubmed: 5568639.

22. Goldman SA, Nottebohm F. Neuronal production, migration, and differentiation in a vocal control nucleus of the adult female canary brain. Proc Natl Acad Sci U S A. 1983; 80(8): 2390-2394, indexed in Pubmed: 6572982.

23. Hassan SM, Moussa EA, Cartwright AL. Variations by sex in anatomical and morphological features of the tongue of Egyptian goose (Alopochen aegyptiacus). Cells Tissues Organs. 2010; 191(2): 161-165, doi: 10.1159/000223231, indexed in Pubmed: 19494477.

24. Iwasaki S. Fine structure of the dorsal lingual epithelium of the little tern, Sterna albifrons Pallas (Aves, Lari). J Morphol. 1992; 212(1): 13-26, doi: 10.1002/jmor.1052120103, indexed in Pubmed: 1375296.

25. Iwasaki Si. Evolution of the structure and function of the vertebrate tongue. J Anat. 2002; 201(1): 1-13, doi: 10.1046/j.1469-7580.2002.00073.x, indexed in Pubmed: 12171472.

26. Iwasaki S, Asami T, Chiba A. Ultrastructural study of the keratinization of the dorsal epithelium of the tongue of Middendorff's bean goose, Anser fabalis middendorffii (Anseres, Antidae). Anat Rec. 1997; 247(2): 149-163, indexed in Pubmed: 9025994.

27. Jackowiak H, Skieresz-Szewczyk K, Godynicki S, et al. Functional morphology of the tongue in the domestic goose (Anser anser f. domestica). Anat Rec (Hoboken). 2011; 294(9): 1574-1584, doi: 10.1002/ar.21447, indexed in Pubmed: 21830308.

28. Kirn JR, Fishman Y, Sasportas K, et al. Fate of new neurons in adult canary high vocal center during the first 30 days after their formation. J Comp Neurol. 1999; 411(3): 487-494, doi: 10.1002/(SICI)1096-9861(19990830)411:3<487::AIDCNE10>3.0.CO;2-M, indexed in Pubmed: 10413781.

29. Kobayashi K, Kumakura M, Yoshimura K, et al. Fine structure of the tongue and lingual papillae of the penguin.
Arch Histol Cytol. 1998; 61(1): 37-46, indexed in Pubmed: 9557966.

30. Lev R, Spicer SS. Specific staining of sulphate groups with alcian blue at low ph. J Histochem Cytochem. 1964; 12: 309, doi: 10.1177/12.4.309, indexed in Pubmed: 14187344.

31. Liman N, Bayram G, Koçak M. Histological and histochemical studies on the lingual, preglottal and laryngeal salivary glands of the Japanese quail (Coturnix coturnix japonica) at the post-hatching period. Anat Histol Embryol. 2001; 30(6): 367-373, doi: 10.1046/j.1439-0264.2001.00353.x, indexed in Pubmed: 11820407.

32. Martinez M, Stefanini MA, Martinez FE, et al. Morphologıcal study of the tongue of budgerigar (Melopsittacusundulatus). Int J Morphol. 2003; 21(2), doi: 10.4067/s071795022003000200004.

33. Matsuo R. Role of saliva in the maintenance of taste sensitivity. Crit Rev Oral Biol Med. 2000; 11(2): 216-229, doi: 10.11 77/10454411000110020501.

34. Mc Lelland J. Apparatus Digestorius. In: Baumel JJ (ed.). Handbook of avian anatomy: Nomina Anatomica Avium. 2nd Ed. Publications of the Nuttall Ornithological Club, Massachusetts 1993: 301-321.

35. McManus JGA, Mowry RW. Staining methods: Histological and Histochemcial. Harper and Row, New York 1964.

36. Mowry RW. Alcian blue techniques for the histochemical study of acidic carbohydrates. J Histochem Cytochem. 1956; 4: 407-408.

37. Nixdorf BE, Davis SS, DeVoogd TJ. Morphology of Golgi-impregnated neurons in hyperstriatum ventralis, pars caudalis in adult male and female canaries. J Comp Neurol. 1989; 284(3): 337-349, doi: 10.1002/cne.902840302, indexed in Pubmed: 2474004.

38. Onuk B, Tütüncü $S$, Kabak M, et al. Macroanatomic, light microscopic, and scanning electron microscopic studies of the tongue in the seagull (Larus fuscus) and common buzzard (Buteo buteo). Acta Zool-Stockholm. 2015; 96(1): 60-66, doi: 10.1111/azo.12051.

39. Parchami A, Dehkordi RAF. Lingual Structure in the Domestic Pigeon (Columba Livia Domestica): A Light and Scanning Electron Microscopic Study. WASJ. 2011; 12(9): 1517-1522.

40. Parchami A, Dehkordi RAF, Bahadoran S. Fine Structure of the Dorsal Lingual Epithelium of the Common Quail (Coturnixcoturnix). WASJ. 2010; 10(10): 1185-1189.

41. Parchami A, Dehkordi RAF, Bahadoran S. Scanning Electron Microscopy of the Tongue in the Golden Eagle Aquila chrisaetos (Aves: Falconiformes: Accipitridae). WJZ. 2010; 5(4): 257-263.

42. Paton JA, Nottebohm FN. Neurons generated in the adult brain are recruited into functional circuits. Science. 1984; 225(4666): 1046-1048, doi: 10.1126/science.6474166, indexed in Pubmed: 6474166.

43. Spicer SS. A correlative study of the histochemical properties of rodent acid mucopolysaccharides. J Histochem Cytochem. 1960; 8: 18-35, doi: 10.1177/8.1.18, indexed in Pubmed: 13833306.

44. Spicer SS, Horn RG, Leppi TJ. Histochemistry of connective tissue mucopolysaccharides. In: Wagner BM, Smith DE (eds). The Connective Tissue William and Wilkin Co, Baltimore. 1967: 251-303.

45. Taib NT, Jarrard BM. Histological and histochemical characterization of the lingual salivary glands of the quail, coturnixcoturnix. Saudy J Bio Sci. 2008; 5(2): 33-41.

46. Totty BA. Chapter 10: Mucins. In: Bancroft J, Gamble M (eds.): Theory and Practice of Histological Techniques. 5th Ed. Churchill Livingstone, Toronto 2002: 163-200. 